\title{
How Gamification is Being Implemented in MOOCs? A Systematic Literature Review
}

\author{
Alejandro Ortega-Arranz, Juan A. Muñoz-Cristóbal, Alejandra \\ Martínez-Monés, Miguel L. Bote-Lorenzo and Juan I. Asensio-Pérez \\ GSIC-EMIC Research Group, Universidad de Valladolid, Spain \\ \{alex|juanmunoz\}@gsic.uva.es, amartine@infor.uva.es, \\ \{migbot|juaase\}@tel.uva.es
}

\begin{abstract}
Although MOOCs are being established as a very popular technology to support learning, they are often criticized for their lack of support to active pedagogies and the high drop-out rates. One approach to face this problem is gamification, due to the promising benefits already shown at small-scale environments. Attending to the current and growing use of game elements in MOOCs, this paper presents a systematic literature review of the usage of gamification in MOOCs, aimed at analyzing how gamification is being implemented in MOOCs, and to identify unexplored research opportunities in this field. The results show that gamification is still at an early stage in MOOCs, and it is being implemented in similar ways to those at small scale contexts.
\end{abstract}

Keywords: Gamification, MOOCs, Literature review, Game elements.

\section{Introduction}

Massive open online courses (MOOCs) are a form of global education that is increasing their popularity over the last years. As a consequence, there is a growing research interest around the MOOC phenomenon, its consequences, and potential benefits [17]. However, the research community also perceives important shortcomings in MOOCs such as the high students' drop-out rates [11], the lack of students' motivation, engagement, and interaction [12] or the lack of active learning [17]. One of the approaches followed to address the aforementioned problems is gamification.

Gamification is defined as the inclusion of elements and structures that frequently appear in games (e.g., narrative, badges, missions) in non-game contexts [5]. Specifically, the gamification in education (gamification from now on) has shown potential benefits in non-massive contexts (e.g., increase students' motivation and engagement) to overcome such current MOOCs' issues (e.g., high drop-out rates) [4][8][7]. However, MOOCs present some peculiarities that may affect the outcomes shown by gamification in other educational contexts and scales; as well as the ways in which these gamifications are designed, implemented and enacted. For example, the different students' background, motivation and intentions can make the design of rewarding criteria more difficult; 
Ortega-Arranz, A., Muñoz-Cristóbal, J. A., Martínez-Monés, A., Bote-Lorenzo, M. L., \& AsensioPérez, J. I. (2017). How Gamification is Being Implemented in MOOCs? A Systematic Literature Review. In Proc. of the 12th European Conference on Technology Enhanced Learning (accepted)

the high probability of many online students connected at the same time open new possibilities of collaborative and competitive online gamifications; the high drop-out rates forces teachers in many cases to design and implement individual gamifications; or the necessity of intelligent and automated gamification, since MOOC instructors cannot draw the attention of each student independently.

Attending to the current and growing interest in the use of gamification in MOOCs, a systematic literature review can be useful for researchers, instructional designers and teachers, to be aware of the work done so far, and to identify issues that need further work. There are already several literature reviews regarding the current state of MOOCs [14][10][12][16]. However, these reviews do not focus on the use of game elements or gamification in such contexts. There are also literature reviews about gamification, focused on small scale and which cover a very limited number of studies about the use of gamification in MOOCs $[4][8][1][7][6]$.

This document presents a systematic literature review $(S L R)$ aiming to explore which is the current state of the implementation of gamification in MOOCs. The next section describes the methodology and protocol followed, including the search strategy, the inclusion/exclusion criteria and the data extraction procedure. Sec. 3 discusses the results obtained. Finally, the conclusions and future research lines are outlined in Sec. 4.

\section{Review Methodology}

The review methodology followed to carry out this SLR is described in Kitchenham and Charters (2007) [13] which has been already employed in previous surveys in technology-enhanced learning. This methodology structures the SLR in three phases (i.e., planning, conducting, reporting) providing guidelines for key issues such as the definition of the search strategy and study selection. In our case, the selected databases were ACM Digital Library, IEEE Xplore Digital Library, Science Direct, Scopus and Springer Link, since the authors consider that these databases are the most relevant databases in the topic field. Moreover, other articles not stored in these databases but cited in the retrieved publications have been also included in the review. The search includes journal publications, conference proceedings, books, book chapters, technical reports and thesis, trying to avoid possible bias.

The search string used was $<$ gamif $^{*}>$ AND $<*$ MOOC $^{*}>$ to be found in the title, abstracts or keywords without any time restrictions. Therefore, publications with derivations of the gamification term such as gamified or gamify and with derivations of the MOOC term such as $c M O O C$ or MOOCs are also included in the search. The inclusion criterion was publications where the use of gamification in MOOCs is a central topic, i.e., gamification is discussed or studied in the work. The retrieved publications were reviewed based on the title first, abstract second, and finally, the whole document to check if the publications meet the inclusion criteria.

Thirty six publications were finally selected. As it is shown in Fig. 1, from 2014 the number of publications regarding gamification in MOOCs has slightly 


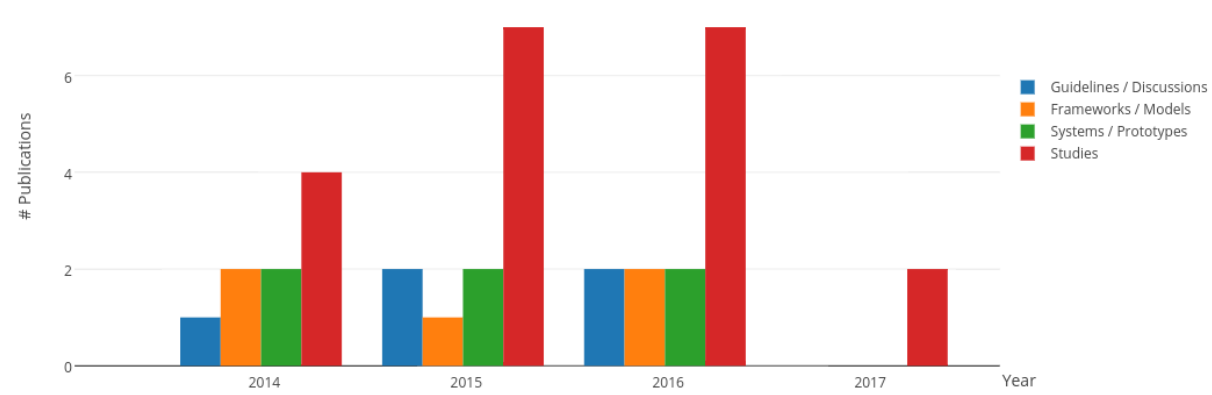

Fig. 1. Distribution of publications attending to the year and type of proposal.

been increasing. However, the low number of publications in scientific journals (4) and the high number of publications in conferences and symposia (24), book chapters (3) and workshops (3) suggest that gamification in MOOCs is still at an early stage. The remaining documents are (1) technical report, and (1) master thesis. Two of the thirty six selected publications extend the work of previous publications also considered for the literature review. Therefore, the resulting number of works analyzed in this paper is thirty four ${ }^{1}$.

\section{Results}

The analysis of the implementation of gamification in MOOCs has been subdivided into: (a) the MOOC platforms used, (b) the proposed game elements, and (c) the students' actions associated to such elements.

Currently, many MOOC platforms do not allow the implementation of game elements into their courses by default. In that sense, Hansch et al. (2015) made an empirical analysis of the gamification capabilities of several massive online platforms, including some MOOC platforms such as FutureLearn, NovoEd, or OpenHPI [9]. In the reviewed works, most of the models/frameworks, prototypes/systems and studies are proposed to be evaluated or are finally evaluated in educational platforms. On the one hand, in the works that use Moodle (3), OpenHPI (2), OpenLearn (1), Claroline Connect (1), iMOOX (1), and Quizlet (1), the gamification was either not evaluated in real environments or evaluated in non massive-scale contexts (i.e., with less than 500 enrolled students). On the other hand, there are several works evaluated in real contexts involving the educational platforms: Telescopio (2), ECO platform (1), Canvas Network (1), Coorpacademy (1), Coursera (1) and MiríadaX (1). Therefore, although there are some educational platforms with gamification capabilities, the effects of gamification in real MOOC contexts have not been thoroughly explored yet.

The decision of which game elements to use and how they are going to interact with the students are important considerations during the design and enactment phases of MOOCs. Fig. 2 shows the game elements implemented or

\footnotetext{
${ }^{1}$ The selected publications and the extracted data is accessible at: https://owncloud.gsic.uva.es/index.php/s/YRje3C1UHghvmG8
} 
Ortega-Arranz, A., Muñoz-Cristóbal, J. A., Martínez-Monés, A., Bote-Lorenzo, M. L., \& AsensioPérez, J. I. (2017). How Gamification is Being Implemented in MOOCs? A Systematic Literature Review. In Proc. of the 12th European Conference on Technology Enhanced Learning (accepted)

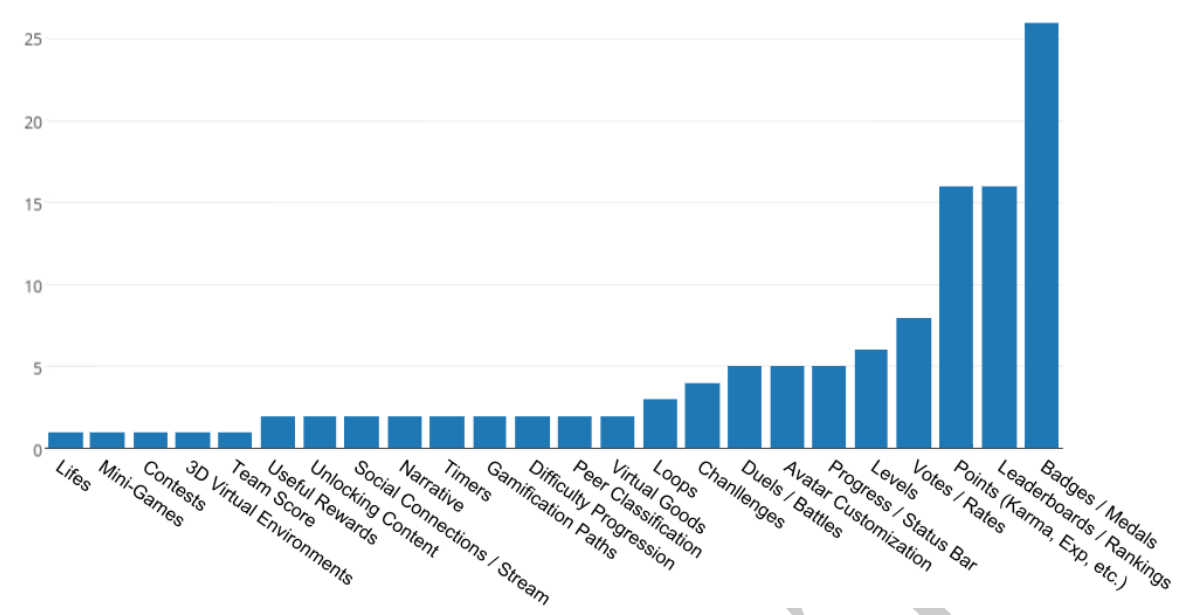

Fig. 2. Game mechanics proposed for the usage of gamification in MOOCs.

proposed to be employed in MOOCs. The top used game elements in MOOCs are points, badges and leaderboards (PBL), similarly to what is shown by other gamification reviews focused on small scale [7][6]. Also, we can see that some game elements that are not frequently implemented in small-scale contexts are gaining importance in MOOCs such as duels, ratings, status bars and avatar customizations. In this sense, Chang and Wei (2016) [2] classify the game elements used in MOOCs regarding their engagement level based on the results of a survey to more than 5.000 MOOC students. Points, badges and team leaderboards are in the top 5 of the most engaging game elements in MOOCs. Nevertheless, there are some other top engagement game elements such as virtual goods and memory-game interactions that have not been highly explored in MOOCs. Further work is needed to understand why PBL are the most used elements even when they have been criticized by some researchers [15], and how can other top engaging game elements be implemented in MOOCs.

While some game elements can be independent of the students' performance such as narrative or 3D graphics, other elements are associated with the actions performed by the students in the learning environments (e.g., the requirements behind the rewards). Fig. 3 shows the students' rewarded actions found in the reviewed works. The most frequent students' actions related to gamification are individual actions that can involve interaction with other students: contributing to forums, completing assignments and modules, and rating other students' comments and content. Most of the students' actions in MOOCs that are related to game elements are automatically analyzed and processed to check if the rewards have to be issued. Few works such as Cross et al. (2014) do the rewarding process manually. In this work, students are rewarded with a badge when other members of the team manually assess the positive contribution to the teamwork [3]. 


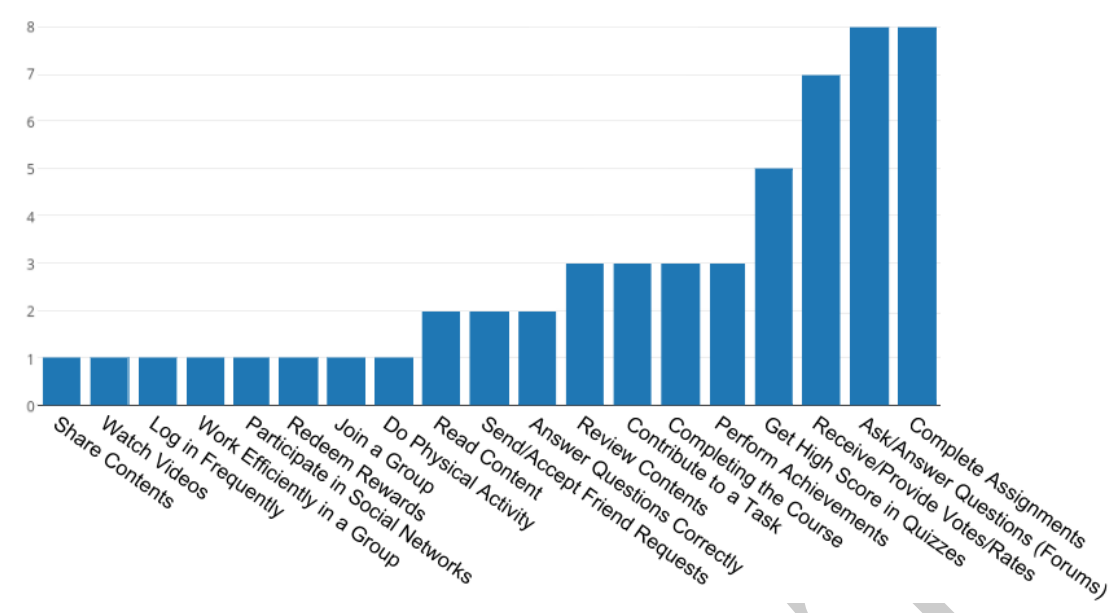

Fig. 3. Students' actions associated to game elements in MOOCs.

\section{Conclusions and Future Work}

This literature review has analyzed the most relevant contributions on the use of gamification in MOOCs, identifying the current state of the art on how gamification is being implemented in MOOCs. Gamification has been proposed and tested in few MOOC platforms, mainly by means of points, badges and leaderboards. These game elements are frequently related to individual student actions such as contributing to forums, completing assignments and modules, and rating other students' comments and content. Further work is needed to analyze the relationship among the gamification design purposes, the game elements and the students' actions since most existing works focus on the analysis of the gamification effects instead of understanding their correlation with the design and implementation decisions.

The review carried out shows that the game elements implemented in MOOCs and rewarded actions are similar to those used in small-scale educational contexts (e.g., PBL, completing assignments). However, there exists some game elements that are gaining presence in MOOCs such as rates, duels or avatar customizations. Another important difference with the small scale is the scarcity of empirical studies exploring the effects of gamification in authentic MOOC-like learning situations. Further work and empirical studies are necessary to understand the effectiveness of different gamification purposes, game elements, and the students' actions on which they are based.

\section{Acknowledgements}

This research has been partially supported by the Junta de Castilla y León (VA082U16) and Ministerio de Economía y Competitividad (TIN2014-53199C3-2-R). The authors thank the GSIC-EMIC research team for their ideas and support and the "Movilidad Doctorandos UVa 2017" grant program. 
Ortega-Arranz, A., Muñoz-Cristóbal, J. A., Martínez-Monés, A., Bote-Lorenzo, M. L., \& AsensioPérez, J. I. (2017). How Gamification is Being Implemented in MOOCs? A Systematic Literature Review. In Proc. of the 12th European Conference on Technology Enhanced Learning (accepted)

\section{References}

1. Caponetto, I., Earp, J., Ott, M.: Gamification and Education: A Literature Review. In: Proc. of the 8th European Conference on Games Based Learning. pp. 50-57 (2014)

2. Chang, J.W., Wei, H.Y.: Exploring Engaging Gamification Mechanics in Massive Online Open courses. Educational Technology \& Society 19(2), 177-203 (2016)

3. Cross, S., Whitelock, D., Galley, R.: The use, role and reception of open badges as a method for formative and summative reward in two Massive Open Online Courses. International Journal of e-Assessment 4(1) (2014)

4. De Sousa Borges, S., Durelli, V., Reis, H., Isotani, S.: A systematic mapping on gamification applied to education. In: Proceedings of the 29th Annual ACM Symposium on Applied Computing. pp. 216-222. ACM (2014)

5. Deterding, S., Dixon, D., Khaled, R., Nacke, L.: From Game Design Elements to Gamefulness: Defining Gamification. In: Proc. of the 15th ACM International Academic MindTrek Conference: Envisioning Future Media Environments. pp. 9$15(2011)$

6. Dichev, C., Dicheva, D.: Gamifying education: what is known, what is believed and what remains uncertain: a critical review. International Journal of Educational Technology in Higher Education 14(1), 9 (2017)

7. Dicheva, D., Dichev, C., Agre, G., Angelova, G.: Gamification in Education: A Systematic Mapping Study. Educational Technology \& Society, 18(3) (2015)

8. Hamari, J., Koivisto, J., Sarsa, H.: Does gamification work?-a literature review of empirical studies on gamification. In: Proc. of 47th Hawaii International Conference on System Sciences. pp. 3025-3034. IEEE (2014)

9. Hansch, A., Newman, C., Schildhauer, T.: Fostering Engagement with Gamification: Review of Current Practices on Online Learning Platforms. HIIG Discussion Paper Series (2015)

10. Jacoby, J.: The disruptive potential of the Massive Open Online Course: A literature review. Journal of Open Flexible and Distance Learning 18(1), 73-85 (2014)

11. Jordan, K.: Initial trends in enrolment and completion of massive open online courses. The International Review of Research in Open and Distributed Learning 15(1) (2014)

12. Khalil, H., Ebner, M.: MOOCs completion rates and possible methods to improve retention-A literature review. In: Proc. of the World Conference on Educational Multimedia, Hypermedia and Telecommunications. pp. 1305-1313. No. 1 (2014)

13. Kitchenham, B., Charters, S.: Guidelines for performing systematic literature reviews in software engineering. In: Technical report, Ver. 2.3 EBSE (2007)

14. Liyanagunawardena, T.R., Adams, A.A., Williams, S.A.: MOOCs: A systematic study of the published literature 2008-2012. The International Review of Research in Open and Distributed Learning 14(3), 202-227 (2013)

15. Robertson, M.: Can't play, won't play. Hide \& Seek 6. Available at http://kotaku.com/5686393/cant-play-wont-play accessed: June 2017 (2010)

16. Veletsianos, G., Shepherdson, P.: A Systematic Analysis and Synthesis of the Empirical MOOC Literature Published in 2013-2015. The International Review of Research in Open and Distributed Learning 17(2) (2016)

17. Yuan, L., Powell, S.: MOOCs and open education: Implications for higher education. Retrieved from: http://publications.cetis.org.uk/wpcontent/uploads/2013/03/MOOCs-and-Open-Education.pdf, accesed January, 2017 (2013) 